\title{
Pituitary Self-priming Actions of Gonadotropin-releasing Hormone \\ Kinetics of Estradiol's Potentiating Effects on Gonadotropin-releasing Hormone-Facilitated Luteinizing Hormone and Follicle-stimulating Hormone Release in Healthy Postmenopausal Women
}

\author{
Johannes D. Veldhuis, William S. Evans, Alan D. Rogol, Lisa Kolp, Michael O. Thomer, and Paul Stumpf* \\ Departments of Internal Medicine, Pharmacology, Pediatrics, and Obstetrics and Gynecology, University of Virginia School of Medicine, \\ Charlottesville, Virginia 22908; and *Department of Obstetrics and Gynecology, Jersey Shore Medical Center, Neptune, New Jersey 07753
}

\begin{abstract}
We examined the kinetically distinct characteristics of estradiol's effects upon pituitary luteinizing hormone (LH) and folliclestimulating hormone (FSH) release in response to pulses of exogenous gonadotropin-releasing hormone (GnRH) in healthy postmenopausal individuals. The putative self-priming actions of GnRH on LH and FSH release were tested by intravenous injections of equal paired doses of $\mathrm{GnRH}(10 \mu \mathrm{g})$ before and after $1,5,10$, and $30 \mathrm{~d}$ of pure estradiol-17 $\beta$ delivery via an intravaginal silastic ring. Self-priming actions of $\mathbf{G n R H}$, as defined by heightened gonadotropin release in response to the second pulse of GnRH compared with the first, were completely absent in the hypoestrogenemic state. However, estradiol administration unmasked GnRH self-priming in a time-dependent fashion, with maximal expression after 5 and $10 \mathrm{~d}$ of steroid replacement, followed by attenuation by $30 \mathrm{~d}$. Since estradiol's modulation of GnRH action was expressed differentially on $\mathrm{LH}$ and FSH release, we suggest that such facilitation of GnRHstimulated pituitary LH and FSH release may provide an additional mechanism for dissociated secretion of gonadotropic hormones in health or disease.
\end{abstract}

\section{Introduction}

Under certain physiological conditions, repetitive stimulation of the anterior pituitary gland by serial pulses of gonadotropinreleasing hormone $(\mathrm{GnRH})^{1}$ results in marked potentiation of gonadotropin release (1-5). This ability of repetitive GnRH stimulation to facilitate pituitary responsiveness has been referred to as the "self-priming" action of this hypothalamic decapeptide (1). Studies in a variety of experimental animals have suggested that such amplifying effects of serial GnRH stimulation may be critically important to the genesis of the preovulatory surge-like release of gonadotropic hormones during the final stages of follicular development (1-8).

Investigations in ovariectomized rodents subjected to various regimens of sex-steroid hormone replacement have implicated estradiol as one critical determinant of the facilitative effects of

\footnotetext{
Address correspondence to Dr. Veldhuis.

Received for publication 14 November 1985 and in revised form 21 January 1986.
}

1. Abbreviations used in this paper: $\mathrm{FSH}$, follicle-stimulating hormone; GnRH, gonadotropin-releasing hormone; LH, luteinizing hormone.

J. Clin. Invest.

(c) The American Society for Clinical Investigation, Inc.

0021-9738/86/06/1849/08 $\$ 1.00$

Volume 77, June 1986, 1849-1856 repetitive GnRH stimulation on pituitary responsiveness in vivo and in vitro (8-16). Similarly, short-term administration of estrogen to postmenopausal women is accompanied by altered pituitary responsiveness to exogenously infused $\operatorname{GnRH}(17,18)$. Such alterations include either inhibition or facilitation of GnRH actions $(17,18)$. Studies in the follicular phase of the human menstrual cycle further suggest that injected estradiol and/or one or more events associated with follicular maturation can result in either diminished or enhanced pituitary responses to exogenous GnRH stimuli (19-24). However, the ability to relate such alterations in pituitary responsiveness explicitly to estradiol is limited in gonadally intact individuals. In addition, available data have not yet delineated: $(a)$ the kinetics of estrogen's elicitation of self-priming actions of $\mathrm{GnRH} ;(b)$ the extent to which acute responses to single $\mathrm{GnRH}$ injections and $\mathrm{GnRH}$ selfpriming represent temporally distinct events; and $(c)$ the differential self-priming effects of GnRH on LH and FSH release.

In the present study, we have used a model of physiological estradiol replacement and paired exogenous GnRH pulses to test for precise temporal correlations between circulating estradiol levels, basal gonadotropin concentrations, and the GnRH-facilitated release of $\mathrm{LH}$ and FSH. To obviate the confounding influences of unstable serum estradiol concentrations that result after oral or intramuscular estrogen dosing, we have used an estradiol-impregnated silastic ring placed intravaginally. The latter mode of steroid-hormone delivery results in the rapid attainment of steady state serum estradiol concentrations commensurate with those of the mid-to-late follicular phase of the normal menstrual cycle. This paradigm has permitted us to elucidate kinetically distinct characteristics of estradiol's effects on pituitary luteinizing hormone ( $\mathrm{LH})$ and follicle-stimulating hormone (FSH) release in response to exogenous GnRH pulses in previously hypoestrogenemic postmenopausal women.

\section{Methods}

Vaginal rings. Estradiol-containing silastic rings were prepared exactly as described earlier, with a dose of $400 \mathrm{mg}$ of estradiol-17 $\beta$ impregnated in each ring (25).

Subjects. Healthy spontaneously postmenopausal women were studied after provision of written informed consent, approved by the Human Investigation Committee of the University of Virginia School of Medicine. The subjects who participated in this study ranged in age from 55 to 63 $\mathrm{yr}$ (mean, 58 $\pm 2 \mathrm{yr}, n=$ eight women) and were 3-9 yr postmenopausal. Each volunteer underwent a detailed history and physical examination, with the documentation of normal hepatic, renal, and hematologic function, biochemical euthyroidism, and postmenopausal concentrations of gonadotropic hormones. At least 5 wk before study, women were withdrawn from any drugs, including estrogen or sex-steroid hormone treatments.

Blood sampling protocols. Sampling was conducted in the Clinical Research Center of the University of Virginia by withdrawing $2.5 \mathrm{ml}$ 
blood at 15-min intervals for $6 \mathrm{~h}$ beginning at $0800 \mathrm{~h}$. After $2 \mathrm{~h}$ of basal sampling, a dose of $10 \mu \mathrm{g}$ GnRH was administered intravenously by bolus injection. After two more hours, a second dose of $10 \mu \mathrm{g} \mathrm{GnRH}$ was given similarly. The first dose was used to appraise acute pituitary responsiveness. The paired pulses of GnRH were used to test for the emergence and/or disappearance of self-priming actions of GnRH. Selfpriming was defined as an increase in pituitary responsiveness to the second dose of $\mathrm{GnRH}$ compared with the first (see below: data analysis).

Sampling was performed basally (no estrogen treatment), and on days $1,5,10$, and 30 after initiation of estradiol replacement.

Assays. Serum concentrations of $\mathrm{LH}$ and FSH were assayed in duplicate with a dual-label radioimmunoassay (RIA) kit (Clinetics Corporation, Tusten, CA). The sensitivities for $\mathrm{LH}$ and FSH were $1.8 \mathrm{mIU} /$ $\mathrm{ml}$ and $1.4 \mathrm{mIU} / \mathrm{ml}$, respectively. Samples were diluted 1:2 or 1:4 to fall within the least variable region of the displacement curve, where the intraassay coefficients of variation averaged $6.3-8.5 \%$, and interassay variability was $9-14 \%(\mathrm{LH})$ and $5-13 \%$ (FSH). The cross-reactions of LH and FSH with alpha subunit in this assay were $<10 \%$. Serum estradiol levels were quantitated by specific RIA after celite chromatography (26).

Data analyses. Data are expressed as means \pm SEM for the group of eight volunteers. Significant overall treatment effects were sought by analysis of variance with the Newman-Keul's procedure to test for individually significant effects (27). Where indicated, specific a priori comparisons of mean, incremental, or absolute peak (maximal) gonadotropin concentrations were made by paired two-tailed Student's $t$ testing with Bonferonni's correction (27). Fractional (percentage) increases in gonadotropin concentrations for the first and second GnRH-stimulated gonadotropin peaks were compared by the Wilcoxon signed ranks test (27).

To assess the possible contribution of multiple parameters to the magnitude of the gonadotropin response to the second pulse of $\mathrm{GnRH}$, multivariate analysis was employed. Multiple linear regression was performed using the mean peak 2 gonadotropin level as the dependent variable, and the following individual independent variables: $(a)$ the mean basal serum gonadotropin concentration over the $2 \mathrm{~h}$ preceding $\mathrm{GnRH}$ administration; (b) the mean gonadotropin response to the first $\mathrm{GnRH}$ pulse; and $(c)$ the simultaneous serum estradiol concentration. In this statistical model, individually significant correlations as well as partial and multiple linear correlations were sought. This permitted us to evaluate the most significant contributors to the amplitude of the gonadotropin response to the second $\mathrm{GnRH}$ pulse at various times after (or before) estradiol administration.

\section{Results}

\section{Serum estradiol concentrations}

Serum estradiol concentrations in the eight women varied significantly over time $(P<0.001)$ in the manner depicted in Fig. 1 . There was an approximately 25 -fold increase in mean serum estradiol concentrations within $24 \mathrm{~h}$ of intravaginal placement of the estradiol-impregnated silastic ring. On day 5 , this value declined to a significant degree $(P<0.01)$, and then remained stable from day 5 through 30 (serum estradiol concentrations on days 5,10 , and 30 did not differ significantly).

\section{Time-dependent influences of estradiol on basal and GnRH-stimulated LH and FSH concentrations}

The temporal profiles of mean serum LH and FSH concentrations derived from eight women sampled at 15 -min intervals for $6 \mathrm{~h}$ before estradiol treatment (basal day 0 ) and on days 1,5 , 10, and 30 of estradiol administration are shown in Fig. $2 A$ and $B$. In each panel, the curve depicting mean serum $\mathrm{LH}$ and $\mathrm{FSH}$ concentrations on day 0 is reproduced for comparison with levels observed on the various days of estradiol administration.

To assess time-dependent changes in baseline (pre-GnRH)

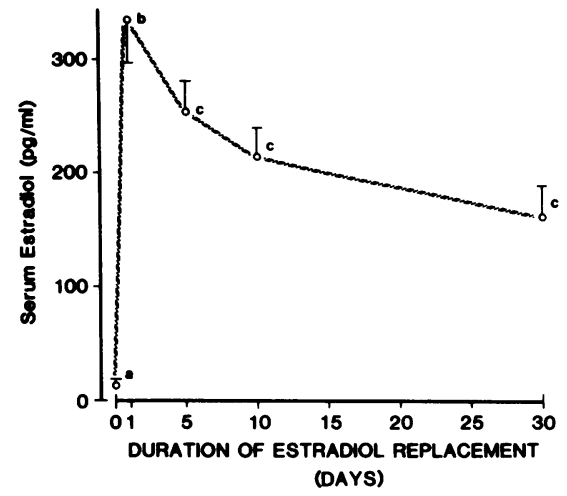

Figure 1. Serum estradiol concentrations attained after intravaginal placement of a silastic ring containing $\mathbf{4 0 0} \mathrm{mg}$ pure crystalline estradiol- $17 \beta$. Serum concentrations of estradiol were measured basally (day 0 ) and on day 1, 5, 10, and 30 of estradiol replacement. Data are means $\pm \operatorname{SEM}$ ( $n=8$ women). Different superscripts denote significantly different serum estradiol concentrations.

gonadotropin concentrations in relation to estradiol replacement, means for the 2-h intervals preceding GnRH injections were analyzed over the five study sessions. As shown in Fig. 3 (top), baseline serum LH concentrations declined within $24 \mathrm{~h}$ of estradiol replacement $(P=0.004$ treatment effect). Mean serum LH concentrations after the first dose of GnRH (1015-1200, peak 1) and after the second dose of GnRH (1215-1400, peak 2) are also summarized in Fig. 3 (middle and bottom). Mean values for peak 1 and peak 2 exhibited significant biphasic changes in response to estradiol replacement $(P=0.015$ for peak 1 , and $P=0.004$ for peak 2).

Mean 2-h baseline serum FSH concentrations also decreased significantly within $24 \mathrm{~h}$ of estradiol replacement $(P<0.001$ treatment effect over time): Fig. 3. Mean FSH concentrations in peak 1 and peak 2 (bottom left) similarly declined progressively during the time course of estradiol replacement $(P<0.001)$.

Fig. 3 also contrasts the patterns observed for mean $\mathrm{LH}$ and FSH concentrations over time. Baseline LH and FSH concentrations differed significantly from each other, with FSH levels exceeding those of $\mathrm{LH}$ at all times except on day 10. On the other hand, mean GnRH-stimulated gonadotropin peak 1 values were similar for LH and FSH at all time points, except on day 30 when FSH peak 1 values exceeded corresponding LH peak 1 levels significantly. In addition, mean GnRH-stimulated LH peak 2 values significantly exceeded those of FSH peak 2 on days 5 and 10 (but not on days 1 or 30 ) of estradiol administration, exemplifying the prominent self-priming actions of GnRH on LH release (discussed further below).

Influence of estradiol on the self-priming action of GnRH: comparison of peak 2 and peak 1 properties

To evaluate the self-priming actions of $\mathrm{GnRH}$, the properties of peak 2 were compared with those of peak 1 . Self-priming by GnRH was defined as a significantly greater gonadotropin response to the second pulse of GnRH (peak 2) compared to the first (peak 1). We have compared peak 2 and peak 1 in relation to the following characteristics: $(a)$ mean $(2-\mathrm{h})$ gonadotropin concentrations; $(b)$ absolute maximal gonadotropin concentrations attained within the peak $(\mathrm{mIU} / \mathrm{ml}) ;(c)$ incremental $(\mathrm{mIU} /$ $\mathrm{ml})$ increases; and $(d)$ percentage increases. These separate analyses of the relationship of peak 2 to peak 1 have permitted us 
A

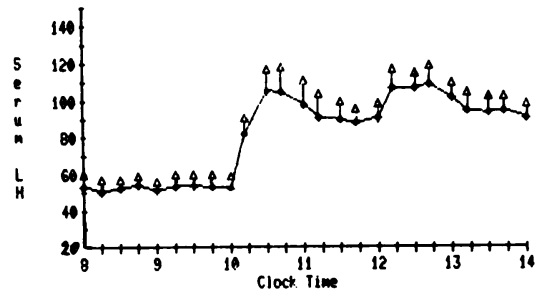

Basal versus Day 1

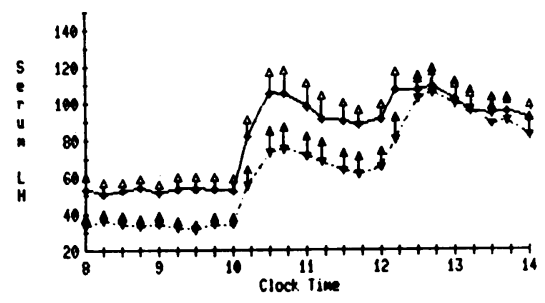

Basal versus Day 10

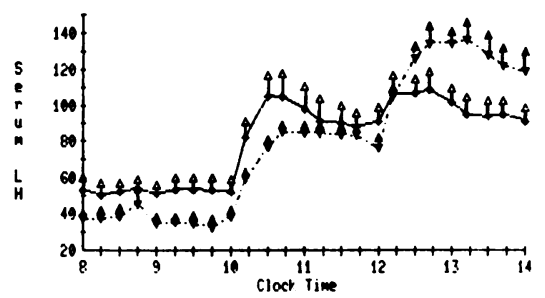

Basal versus Day 5

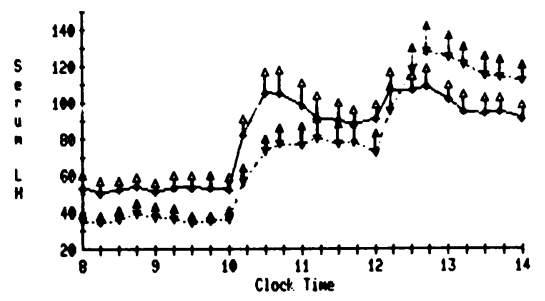

Basal versus Day 30

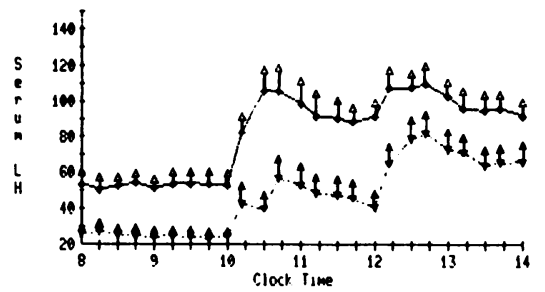

B

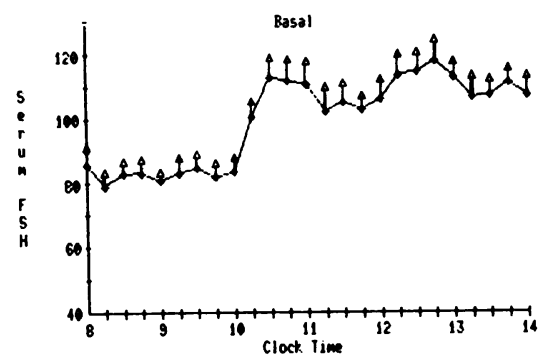

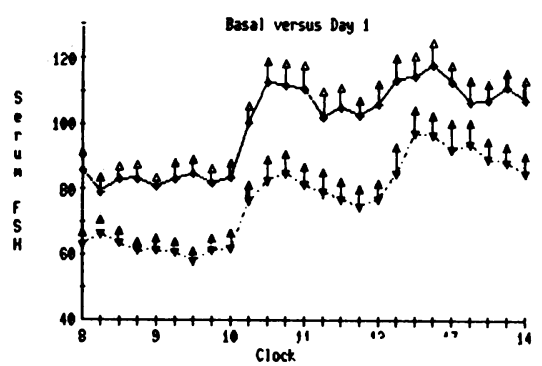

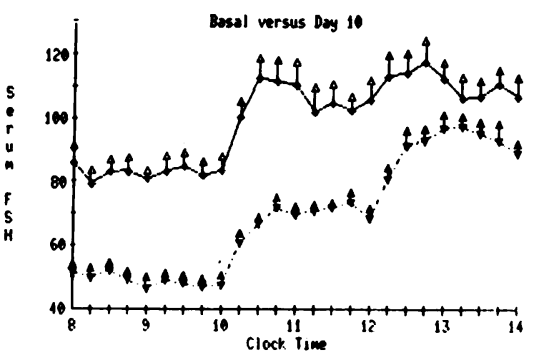

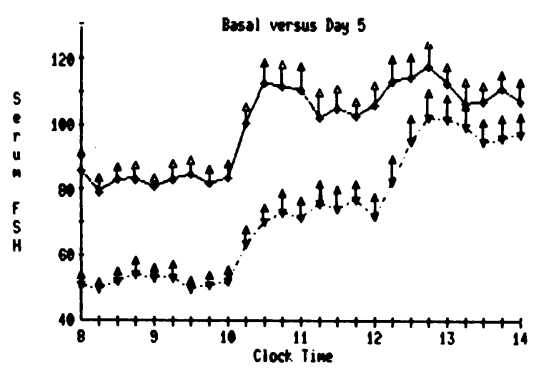

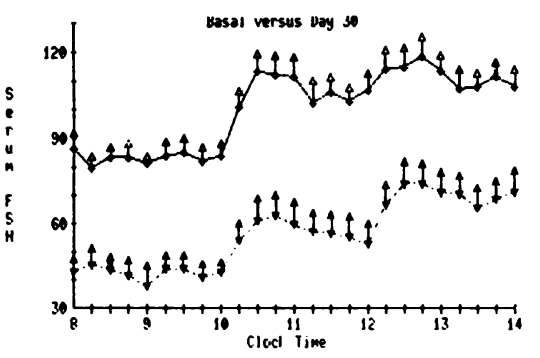

Figure 2. Individual time-courses for serum LH $(A)$ and FSH $(B)$ concentrations in postmenopausal women sampled at 15 -min intervals for $6 \mathrm{~h}$ before estrogen replacement and at various intervals after intravaginal placement of an estradiol-containing silastic ring. The mean serum immunoactive LH and $\mathrm{FSH}$ concentrations $(\mathrm{mIU} / \mathrm{ml})$ for eight healthy postmenopausal women were determined from blood samples drawn at 15 min intervals over $6 \mathrm{~h}$. The first $2 \mathrm{~h}$ of sampling represented basal conditions $(0800$ $1000 \mathrm{~h})$. Thereafter $(1000 \mathrm{~h}), 10 \mu \mathrm{g}$ of GnRH were administered by intravenous bolus injection, which was repeated $2 \mathrm{~h}$ later $(1200 \mathrm{~h})$. This schedule of sampling and $\mathrm{GnRH}$ administration was repeated on five occasions: a basal day (before the administration of estradiol), and on days 1,5 , 10 , and 30 after intravaginal placement of a silastic ring containing $\mathbf{4 0 0} \mathbf{~ m g}$ of pure estradiol-17 $\beta$. In each figure, the basal (pre-estradiol) time-course for LH or FSH is shown for comparison (solid circles and open triangles). Data are presented as means \pm SEM $(n=8$ subjects). 


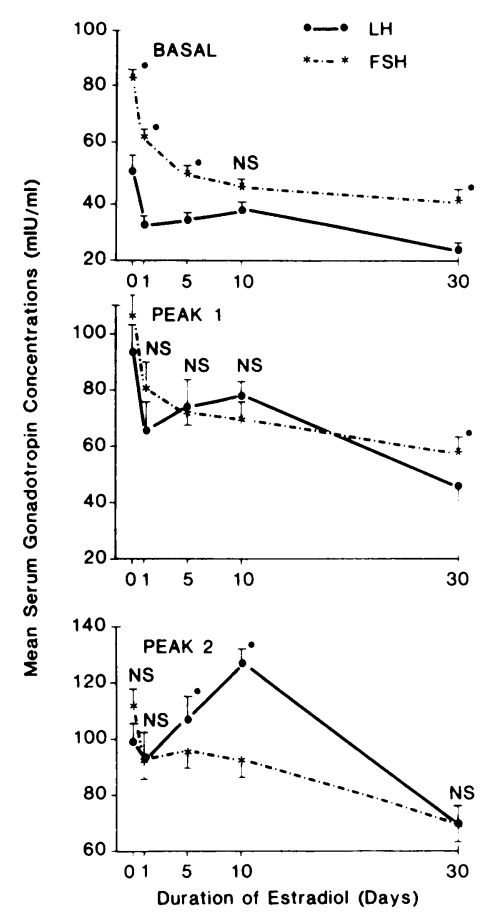

to search for significant time-dependent effects of estradiol on one or more specific properties of the GnRH-stimulated gonadotropin peak.

Mean and maximal amplitudes of gonadotropin peak 1 and peak 2. Mean $\mathrm{LH}$ concentrations in peak 1 compared with peak 2 are presented in Fig. $4 \mathrm{~A}$. Peak 1 and peak 2 are compared under estrogen-deficient conditions (day 0), and on days 1,5 , 10 , and 30 of estradiol replacement. As shown in the left panel of Fig. $4 A$, in the absence of estradiol, peak 1 and peak 2 mean amplitudes were statistically indistinguishable. In particular, the mean $( \pm$ SEM) LH concentration for peak 1 was $93.7 \pm 10.4 \mathrm{mIU} /$ $\mathrm{ml}$ vs. $99.9 \pm 8.7 \mathrm{mIU} / \mathrm{ml}$ for peak 2 . Thus, we could demonstrate no self-priming action of $\mathrm{GnRH}$ in the absence of estradiol replacement.

In contrast, after $24 \mathrm{~h}$ of estradiol administration, mean LH peak 2 concentrations significantly exceeded those of peak 1 ( $P$ $<0.001)$. This self-priming pattern was also observed on days 5,10 , and 30 of estradiol replacement $(P<0.001)$. Moreover, since samples were withdrawn at equally spaced intervals (every $15 \mathrm{~min}$ ), the mean values discussed above are directly proportional to the effective area under the GnRH-stimulated LH peaks. This implies that estradiol influences integrated gonadotropin responses to the first and second GnRH pulses in different ways.

Maximal (absolute peak) LH concentrations attained within peak 1 and peak 2 also did not differ significantly under basal conditions (before estradiol replacement) (Fig. $4 A$, right). However, within $24 \mathrm{~h}$ of estradiol administration, the absolute peak values of $\mathrm{LH}$ achieved in response to the second $\mathrm{GnRH}$ stimulus significantly exceeded those elicited by the first stimulus ( $P$ $<0.001)$. This pattern was sustained to a significant degree on days 5,10 , and $30(P<0.005$ to $P<0.001)$.

In the case of FSH, mean and maximal (absolute peak) FSH concentrations were also compared for peak 1 and peak 2 before and at various times after estradiol replacement (Fig. $4 \mathrm{~B}$ ). Like LH, the magnitude of FSH peak 2 and peak 1 did not differ significantly in the absence of estradiol. However, within $24 \mathrm{~h}$ of estradiol replacement, the mean and maximal amplitudes of
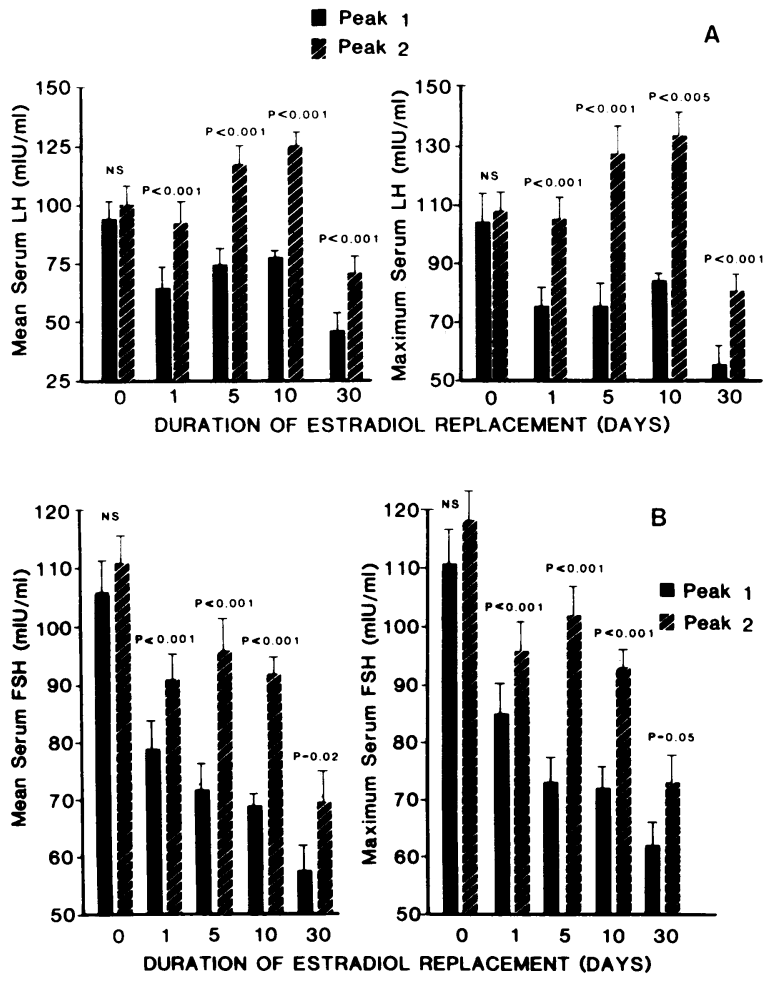

Figure 4. Impact of estradiol replacement on serum gonadotropin concentrations associated with $\mathrm{GnRH}$-stimulated gonadotropin peak 1 or peak 2. Peak 1 and peak 2 were defined as LH $(A)$ and FSH $(B)$ concentrations after the first or second injections of $10 \mu \mathrm{g} \mathrm{GnRH}$. The left panel gives the mean hormone concentration (averaged over $2 \mathrm{~h}$ ), and the right panel gives the maximal (absolute peak) gonadotropin concentration. $P$ values denote significant differences between peak 1 and peak 2 amplitudes.

FSH peak 2 significantly exceeded those of peak $1(P<0.001)$. Such differences were sustained for days 5,10 , and 30 of estradiol replacement $(P=0.05$ to $P<0.001)$.

Incremental and fractional amplitudes of gonadotropin peak 1 and peak 2. The amplitudes of the first and second GnRHstimulated gonadotropin peaks were compared in relation to incremental ( $\mathrm{mIU} / \mathrm{ml}$ difference) and percentage (fractional) increases, which were defined as follows. The incremental increase for peak 1 was taken as the mean value of peak 1 minus the mean value of the corresponding baseline (0800-1000) hormone concentration. The incremental value for peak 2 was defined as the mean value of peak 2 minus the nadir for peak 1 (measured at 1200 , just before injection of the second dose of $\mathrm{GnRH}$ ). The percentage increases for peak 1 and peak 2 were defined similarly; $v i z$., as the ratio of mean peak 1 to mean baseline concentrations, and the ratio of mean peak 2 to peak 1 nadir concentrations.

As summarized in Fig. $5 \mathrm{~A}$, before estradiol replacement (day 0 ), the increment of LH peak 1 above baseline significantly exceeded that of LH peak 2 above the peak 1 nadir $(P<0.003)$. However, within $24 \mathrm{~h}$ of treatment with estradiol, the increase of $\mathrm{LH}$ peak 2 over $\mathrm{LH}$ peak 1 nadir was augmented, while the increase of peak 1 over basal declined. Moreover, by day 5 of estradiol replacement, the increment of peak 2 over peak 1 nadir was significantly greater than the increment of peak 1 over basal $(P<0.025)$. This augmentation of the peak 2 amplitude occurred to a lesser and insignificant degree on days 10 and 30 of estradiol 

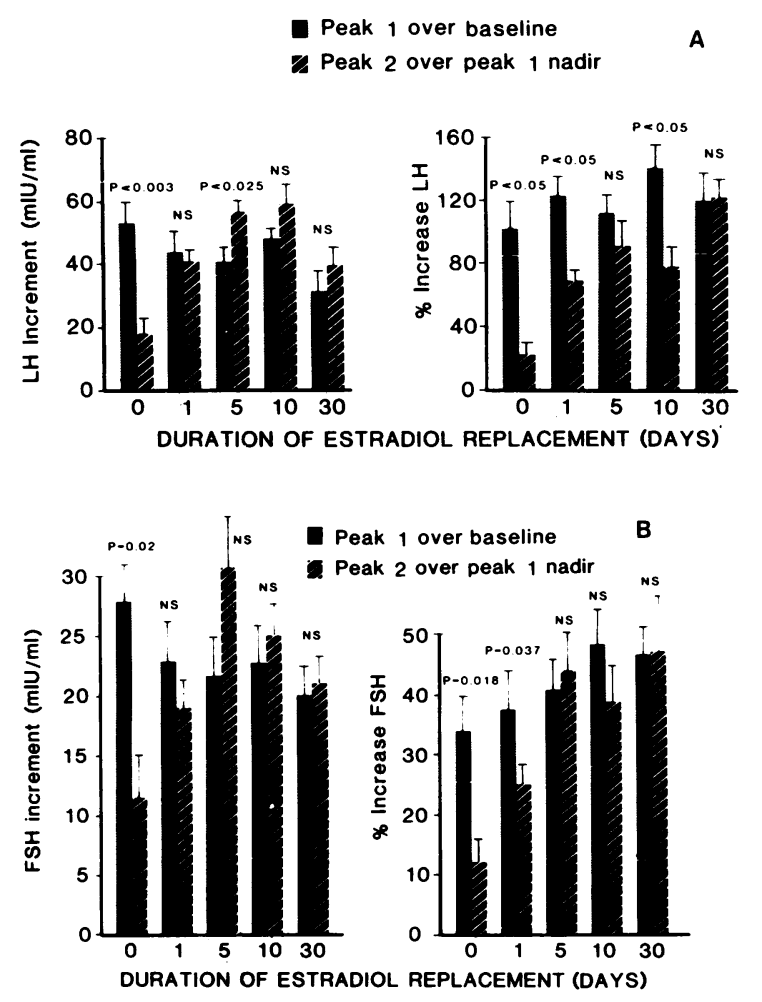

Figure 5. Effects of estradiol upon GnRH-stimulated gonadotropin peak 1 and peak 2 amplitudes expressed as incremental or percentage increases. Data are presented as in Fig. 4, except that the amplitudes of peak 1 and peak 2 are defined either as incremental $(\mathrm{mIU} / \mathrm{ml}$ difference) or as percentage increases. For peak 1, the incremental and percentage increases were measured with respect to mean basal concentrations. For peak 2, the incremental and percentage increases were measured relative to the nadir of peak 1 (taken as $1,200 \mathrm{~h}$, just before the second dose of GnRH). Results are shown for LH $(A)$ and FSH $(B)$ in relation to the duration (days) of estradiol replacement. Data are means $+\operatorname{SEM}$ ( $n=8$ subjects).

replacement. A generally similar pattern relating peak 2 and peak 1 was observed in relation to estradiol replacement when peak amplitudes were expressed as percentage increases (right panel of Fig. $5 \mathrm{~A}$ ).

An analogous temporal pattern was observed for incremental or percentage increases when FSH peak 1 and FSH peak 2 were compared (Fig. 5 B).

\section{Multivariate analysis of principal contributors to the amplitude of the gonadotropin peak 2}

The correlations between mean peak 2 and peak 1 gonadotropin concentrations were appraised for each of the five individual study sessions (day 0 , and days 1, 5, 10, and 30 of estradiol treatment). In each study session, mean peak 2 and peak 1 concentrations were significantly correlated for $\mathrm{LH}$ as well as for FSH $(P<0.001)$. Thus, five individual regression coefficients related mean peak 2 to mean peak 1 values for each gonadotropic hormone (Table I). Within $24 \mathrm{~h}$ of estradiol treatment, the regression coefficient (i.e., slope of the line traversing the origin that related mean $\mathrm{LH}$ peak 2 to mean $\mathrm{LH}$ peak 1 concentrations) increased significantly, and continued to increase to a maximal value on day 10 of estradiol treatment. The overall profile for FSH was similar, but at each time after estrogen treatment the
Table I. Regressions of Mean GnRH-stimulated Gonadotropin Peak 2 on Peak 1 at Various Times after Estradiol Replacement

\begin{tabular}{lll}
\hline $\begin{array}{l}\text { Duration } \\
\text { of estradiol } \\
\text { replacement }\end{array}$ & $\mathrm{LH}^{*}$ & FSH \\
\hline days & & \\
\hline 0 & $1.04 \pm 0.15 \S$ & $1.04 \pm 0.19$ \\
1 & $1.34 \pm 0.16$ & $1.15 \pm 0.04$ \\
5 & $1.53 \pm 0.18$ & $1.33 \pm 0.16$ \\
10 & $1.59 \pm 0.42$ & $1.33 \pm 0.11$ \\
30 & $1.45 \pm 0.19$ & $1.10 \pm 0.20$ \\
\hline
\end{tabular}

* Each linear regression coefficient was significant at $P<0.001$. $\ddagger$ Each linear regression coefficient was significant at $P<0.003$. $\S$ Slopes of the linear regression of mean peak 2 on mean peak 1 . Data are means \pm SEM for the slope of the linear regression $(n=$ eight women studied at each time).

slope of the regression of FSH peak 2 on FSH peak 1 was less than that for LH. Thus, the self-priming action of GnRH (defined here by the relationship of peak 2 to peak 1) depended significantly upon the duration of estradiol treatment. Moreover, GnRH self-priming was more prominent for LH than FSH.

The multivariate relationship between mean LH peak 2 concentrations and the following other parameters was also assessed: baseline LH, mean LH peak 1, and serum estradiol concentrations. This permitted us to test the relative contributions of these parameters to the magnitude of $\mathrm{LH}$ peak 2 at various times before and after estradiol replacement. As shown by the correlation coefficients given in Table II (top), the mean amplitude of LH peak 2 on day 0 (no estradiol) was correlated significantly to three factors: basal $\mathrm{LH}$, mean $\mathrm{LH}$ peak 1 , and estradiol concentrations $(P=0.013)$. The mean amplitude of $\mathrm{LH}$ peak 2 on day 0 was associated most significantly with two parameters: baseline and peak 1 concentrations $(P=0.002)$. In

Table II. Relation of Gonadotropic Peak 2 to Basal,

Peak 1 and/or Serum Estradiol Concentrations

\begin{tabular}{|c|c|c|c|c|}
\hline \multirow[b]{2}{*}{ Condition } & \multicolumn{4}{|c|}{ Partial and multiple correlation } \\
\hline & $\begin{array}{l}\text { Basal, peak } 1 \\
\text { and estradiol }\end{array}$ & $\begin{array}{l}\text { Basal and } \\
\text { peak } 1\end{array}$ & $\begin{array}{l}\text { Basal and } \\
\text { estradiol }\end{array}$ & $\begin{array}{l}\text { Peak } 1 \text { and } \\
\text { estradiol }\end{array}$ \\
\hline \multicolumn{5}{|l|}{ day } \\
\hline 0 & +0.957 & $+0.953^{*}$ & +0.886 & +0.934 \\
\hline $1 \mathrm{LH}$ & +0.977 & +0.976 & +0.916 & $+0.977^{*}$ \\
\hline $5 \mathrm{LH}$ & +0.990 & +0.984 & +0.943 & $+0.989^{*}$ \\
\hline $10 \mathrm{LH}$ & NS & $+0.974^{*}$ & +0.891 & NS \\
\hline $30 \mathrm{LH}$ & NS & $+0.974^{*}$ & +0.972 & +0.971 \\
\hline $0 \mathrm{FSH}$ & NS & $+0.906^{*}$ & NS & +0.885 \\
\hline $1 \mathrm{FSH}$ & +0.998 & $+0.998^{*}$ & +0.875 & +0.997 \\
\hline $5 \mathrm{FSH}$ & +0.960 & $+0.958^{*}$ & +0.869 & +0.949 \\
\hline $10 \mathrm{FSH}$ & NS & $+0.984^{*}$ & NS & +0.979 \\
\hline $30 \mathrm{FSH}$ & NS & +0.939 & $+0.962^{*}$ & +0.950 \\
\hline
\end{tabular}

NS, $P>0.05$ (not significant): $P<0.05$ for all other correlations.

* Greatest $\mathrm{F}$ ratio for that day. 
contrast, after 1 and $5 \mathrm{~d}$ of estradiol administration, the amplitude of LH peak 2 was correlated most significantly to mean LH peak 1 and serum estradiol concentrations $(P<0.001)$. On days 10 and 30 of estradiol administration, peak 2 was described best by its relationship to baseline and $\mathrm{LH}$ peak 1 concentrations $(P=0.003)$. Thus, the statistical correlates of the mean amplitude of $\mathrm{LH}$ peak 2 varied in a distinctive manner over time, with peak 1 amplitude and serum estradiol concentrations being most influential on days 1 and 5, while baseline and peak 1 concentrations were most contributory on days 0,10 , and 30 of estrogen administration.

The preceding overall pattern for $\mathrm{LH}$ differed from that observed in the case of FSH (bottom, Table II), since basal FSH and mean FSH peak 1 concentrations provided the best statistical correlates of the amplitude of FSH peak 2 for days 0, 1, 5, and 10 after estradiol $(P=0.014$ to $P<0.001)$. By day 30 of estradiol, baseline FSH and the serum estradiol concentrations represented the most significant correlates of mean FSH peak 2 levels. These analyses indicate that the correlates of $\mathrm{LH}$ and FSH responsiveness to paired GnRH pulses are distinctively influenced by the relative and time-dependent contributions of baseline gonadotropin concentrations, mean peak 1 gonadotropin concentrations, and concurrent estradiol levels.

\section{Influence of estradiol on total incremental gonadotropin release in response to paired exogenous GnRH pulses}

The time-dependent effects of estradiol on total GnRH-promoted gonadotropin release were estimated by determining the sum of peak 1 and peak 2 increments over basal before and at various times after estradiol administration. Such estimates of total incremental $\mathrm{LH}$ and FSH release are given in Table III for days $0,1,5,10$, and 30 of study. For both LH and FSH, total incremental gonadotropin release was relatively reduced on day 30 . In contrast, on day 10 of estradiol treatment, the total incremental value for GnRH-stimulated $\mathrm{LH}$ release was significantly greater than that on day 0 (pre-estrogen) or day 30 . Similarly, for FSH, the sum of the peak 1 and peak 2 increments on days 5 and 10 significantly exceeded that on day 30 . Thus, estimated total LH and FSH release in response to exogenous paired GnRH pulses varies significantly in relation to the duration of estradiol replacement.

Table III. Time-dependent Influence of Estradiol on Total Incremental Gonadotropin Release in Response to Paired Pulses of Exogenous GnRh

\begin{tabular}{lcl}
\hline $\begin{array}{l}\text { Duration of } \\
\text { estradiol treatment }\end{array}$ & Total LH increments & Total FSH increments \\
\hline days & $\mathrm{mIU} / \mathrm{ml}^{*}$ & $\mathrm{mIU} / \mathrm{m} l^{*}$ \\
0 & $109 \pm 14$ & $64 \pm 8.6$ \\
1 & $114 \pm 16$ & $58 \pm 7.7$ \\
5 & $133 \pm 14$ & $72 \pm 7.9 \S$ \\
10 & $145 \pm 10 \ddagger$ & $68 \pm 6.6 \S$ \\
30 & $88 \pm 15$ & $52 \pm 5.4$ \\
\end{tabular}

\footnotetext{
* Data are means $\pm \operatorname{SEM}(n=$ eight subjects) for the total incremental amplitudes $(\mathrm{mIU} / \mathrm{ml})$ of GnRH-stimulated gonadotropin peaks 1 and 2 at the indicated times before and after estradiol administration. $\ddagger P=0.044$ vs. day 0 or day 30 .

$\S P=0.029$ vs. day 30 .
}

\section{Discussion}

Our results clearly show that estradiol differentially regulates the responsiveness of anterior pituitary LH and FSH release to exogenous GnRH pulses, and that these actions of estradiol are critically time-dependent. Thus, in the estrogen-deprived state, LH reponses to the first and second of paired GnRH pulses did not differ significantly. However, within $24 \mathrm{~h}$ of estradiol administration, the mean and maximal values of $\mathrm{LH}$ elicited by the second GnRH stimulus significantly exceeded those evoked by the first stimulus. This pattern of increased LH release in response to the second, compared with the first, pulse of releasing factor exemplifies the self-priming action of $\mathrm{GnRH}$ (1-5).

Our appraisal of the detailed time-course of estradiol's influence on this self-potentiating action of $\mathrm{GnRH}$ indicates the dynamic nature of estrogen action, which is characterized by the emergence of maximal GnRH self-priming within 5-10 d of increased circulating estradiol concentrations, followed by an attenuation of $\mathrm{GnRH}$ self-priming after $30 \mathrm{~d}$ of continuous estradiol exposure. Moreover, increased GnRH-stimulated LH release after the second pulse of releasing factor was accompanied by parallel changes in total gonadotropin release in response to both GnRH pulses, indicating that self-priming did not simply reflect redistribution of $\mathrm{LH}$ release from a diminishing peak 1 to an expanding peak 2 . Of additional interest, the biphasic pattern of emergence and subsequent attenuation of GnRH selfpriming occurred despite unchanging serum estradiol concentrations over days 5-30 of estrogen administration.

The intravaginal route of estradiol delivery via polysiloxane vehicle results in uniform and selective elevation of serum estradiol concentrations into the normal physiological range characteristic of the mid- to late follicular phase, with a lesser rise in serum estrone concentrations (approximately twofold increase) (28). In response to this estrogenic milieu, serum free testosterone concentrations decline significantly within $5 \mathrm{~d}$ and return to baseline by day $10(28)$. These steroid hormone changes suggest that the self-priming actions of GnRH observed on day 5 of estradiol replacement might reflect the combined impact of an increase in circulating estradiol concentrations as well as a diminution in androgen negative-feedback effects associated with declining serum free testosterone concentration. Although the present data do not permit us to distinguish between these two possibilities unambiguously, the influence of decreased serum free testosterone levels appears to be relatively minimal, since prominent self-priming actions of $\mathrm{GnRH}$ were also observed on day 10 of estradiol administration, when plasma concentrations of free testosterone, total testosterone, dehydroepiandrosterone sulfate, and androstenedione are no different from basal (before estradiol administration) (28). Thus, the dominant steroidal correlate of $\mathrm{GnRH}$ self-priming is estradiol per se. As such, these results may be pertinent to understanding estradiol's regulation of gonadotropin secretory patterns. However, the present model may not necessarily apply in all its details to younger, normally menstruating women.

The ability of estradiol to amplify pituitary responsiveness to paired exogenous pulses of $\mathrm{GnRH}$ in a time-dependent manner could be observed whether GnRH-stimulated gonadotropin peaks were appraised as mean, maximal, incremental, fractional, or total increases above baseline. Although estrogen does not seem to influence the metabolic clearance of GnRH per se (17), the effects of estradiol on GnRH-stimulated LH and FSH release could be modified by estrogen-associated alterations in rates of 
gonadotropin metabolic clearance $(29,30)$. However, estrogen's suppression of mean plasma gonadotropin concentrations would actually tend to accelerate LH clearance, since the metabolic clearance of LH increases at lower serum hormone concentrations (31). This increase in the rate of gonadotropin removal from the circulation would actually render the detection of GnRH self-priming more difficult. Moreover, our analysis of incremental and fractional increases in peak 2 relative to the nadir of peak 1 , which provides the least favorable conditions for detecting self-priming effects of $\mathrm{GnRH}$, still reveals preferential augmentation of GnRH-stimulated gonadotropin peak 2 over peak 1. Such self-priming was maximal on day 5 of sustained estrogen administration. Thus, these different but complementary analyses suggest that estradiol amplifies pituitary responsiveness to paired exogenous pulses of $\mathrm{GnRH}$, and that such amplifying actions of estradiol emerge in a distinct time-dependent fashion in previously hypoestrogenemic postmenopausal women.

Estradiol administration potentiated both GnRH-stimulated LH and FSH release. In comparing the individual time courses of the self-priming actions of GnRH on LH and FSH secretion, we observed a consistently more prominent facilitative effect of estradiol on GnRH-stimulated LH than FSH release independently of how the data were expressed. However, the overall temporal profile of estradiol's potentiation of GnRH action was analogous for $\mathrm{LH}$ and FSH, with maximal GnRH self-priming of gonadotropin release observed after 5 and $10 \mathrm{~d}$ of estradiol replacement.

The statistical correlates of GnRH self-priming varied over time and were also distinguishable for $\mathrm{LH}$ and FSH. In relation to maximal GnRH self-priming of LH release (day 5), the amplitude of GnRH-stimulated peak 2 could be accounted for predominantly by the amplitude of corresponding LH peak 1 and the simultaneous serum estradiol concentration. In contrast, for FSH, the predominant predictors of peak 2 amplitude were basal and peak 1 FSH concentrations. Such multivariate analyses indicated that the individual correlates of GnRH-stimulated LH and FSH release in response to estradiol administration were temporally distinguishable for the two gonadotropic hormones, at least in postmenopausal individuals. This may suggest that different pituitary mechanisms operate to regulate $\mathrm{GnRH}$ selfpriming of LH and FSH. However, independently of the precise mechanisms proposed, our observations document significant differences in the relative self-priming actions of GnRH on LH and FSH release. We suggest that such differences may provide an additional mechanism for dissociated release of gonadotropic hormones under conditions of health or disease.

\section{Acknowledgments}

We thank Chris McNett for her skillful preparation of the manuscript; Paula P. Azimi for the artwork; National Hormone and Pituitary Program for the provision of purified human LH; the Clinetics Corporation for its grant-in-aid in support of the gonadotropin assay kits; E. Elizabeth Taylor and Rebecca Weaver for technical support; Sandra Jackson and the expert nursing staff at the Clinical Research Center at the University of Virginia; and Mr. David Boyd for valued assistance with Clinfo.

This work was supported in part by National Institutes of Health grant No. RR 00847 to the Clinical Research Center of the University of Virginia, by RCDA 1 K04 HD 00634 (JDV), HD 13197 (MOT), HD 0439 (WSE), Diabetes and Research Training Center grant No. 5 P60 AM 22125-05, and National Institutes of Health-supported Clinfo Data Reduction Systems.

\section{References}

1. Aiyer, M. S., S. A. Chiappa, and G. Fink. 1974. A priming effect of luteinizing hormone releasing factor on the anterior pituitary gland in the female rat. J. Endocrinol. 62:573-588.

2. Castro-Vaszquez, A., and S. M. McCann. 1975. Cyclic variations in the increased responsiveness of the pituitary to luteinizing hormonereleasing hormone (LHRH) induced by LHRH. Endocrinology. 97:1318.

3. Fink, G., S. A. Chiappa, and M. S. Aiyer. 1976. Priming effect of luteinizing hormone releasing factor elicited by preoptic stimulation and by intravenous infusion and multiple injections of the synthetic decapeptide. J. Endocrinol. 69:359-372.

4. Pickering, A. J. M. C., and G. Fink. 1976. Priming effect of luteinizing hormone releasing factor: in vitro and in vivo evidence consistent with its dependence upon protein and RNA synthesis. J. Endocrinol. 69:373-379.

5. Pickering, A. J. M. C., and G. Fink. 1977. Priming effect of luteinizing hormone releasing factor with respect to release of follicle-stimulating hormone in vitro and in vivo. J. Endocrinol. 75:155-159.

6. Waring, D. W., and J. L. Turgeon. 1980. Luteinizing hormonereleasing hormone-induced luteinizing hormone secretion in vitro: Cyclic changes in responsiveness and self-priming. Endocrinology. 106:14301436.

7. Gordon, J. H., and S. Reichlin. 1974. Changes in pituitary responsiveness to luteinizing hormone-releasing factor during the rat estrous cycle. Endocrinology. 94:974-978.

8. Speight, A., R. Popkin, A. G. Watts, and G. Fink. 1981. Oestradiol$17 \beta$ increases pituitary responsiveness by a mechanism that involves the release and the priming effect of luteinizing hormone releasing factor. $J$. Endocrinol. 88:301-308.

9. Vilchez-Martinez, J. A., A. Arimura, L. Debeljuk, and A. V. Schally. 1974. Biphasic effect of estradiol benzoate on the pituitary responsiveness of LHRH. Endocrinology. 94:1300-1303.

10. Libertun, C., R. Orias, and S. M. McCann. Biphasic effect of estrogen on the sensitivity of the pituitary to LH-RH (LRF). Endocrinology. 94:1094-1100.

11. Drouin, J., L. Lagace, and F. Labrie. 1976. Estradiol-induced increase of the LH responsiveness to LH releasing hormone (LHRH) in rat anterior pituitary cells in culture. Endocrinology. 99:1477-1481.

12. Goodman, R. L., and E. Knobil. 1981. The sites of action of ovarian steroids in the regulation of LH secretion. Neuroendocrinology. 32:57-63.

13. Clayton, R. N., A. Solano, A. Garcia-Vela, M. L. Dufau, and K. J. Catt. 1980. Regulation of pituitary receptors for gonadotropinreleasing hormone during the rat estrous cycle. Endocrinology. 107:699706.

14. Higuchi, T., and M. Kawakami. 1982. Luteinizing hormone responses to repeated injections of luteinizing hormone releasing hormone in the rat during the oestrous cycle and after ovariectomy with or without oestrogen treatment. J. Endocrinol. 93:161-168.

15. Padmanabhan, V., K. Leung, and E. M. Convey. 1982. Ovarian steroids modulate the self-priming effect of luteinizing hormone-releasing hormone on bovine pituitary cells in vitro. Endocrinology. 110:717-721.

16. Evans, W. S., D. R. Uskavitch, D. L. Kaiser, P. Hellmann, J. L. Borges, and M. O. Thorner. 1984. The self-priming effect of gonadotropinreleasing hormone on luteinizing hormone release: Observations using rat anterior pituitary fragments and dispersed cells continuously perifued in parallel. Endocrinology. 114:861-867.

17. Keye, W. R., and R. B. Jaffe. 1974. Modulation of pituitary gonadotropin response to gonadotropin-releasing hormone by estradiol. J. Clin. Endocrinol. Metab. 38:805-810.

18. Lasley, B. L., C. F. Wang, and S. S. C. Yen. 1975. The effects of estrogen and progesterone on the functional capacity of the gonadotrophs. J. Clin. Endocrinol. Metab. 41:820-826.

19. Yen, S. S. C., G. Vandenberg, R. Rebar, and Y. Ehara. 1972. Variation in pituitary responsiveness to synthetic LRF during different phases of the menstrual cycle. J. Clin. Endocrinol. Metab. 35:931-934. 
20. Shaw, R. W., W. R. Butt, D. R. London, and J. C. Marshall. 1974. Variation in response to synthetic luteinizing hormone-releasing hormone (LHRH) at different phases of the same menstrual cycle in normal women. J. Obstet. Gynaecol. Br. Commonw. 81:632-639.

21. Jaffe, R. B., and W. R. Keye, Jr. 1974. Estradiol augmentation of pituitary responsiveness to gonadotropin-releasing hormone in women. J. Clin. Endocrinol. Metab. 39:850-855.

22. Keye, W. R., Jr., and R. B. Jaffe. 1975. Strength-duration characteristics of estrogen effects on gonadotropin response to gonadotropin releasing hormone in women. I. Effects of varying duration of estradiol administration. J. Clin. Endocrinol. Metab. 41:1003-1008.

23. Young, J. R., and R. B. Jaffe. 1976. Strength-duration characteristics of estrogen effects on gonadotropin-releasing hormone in women. II. Effects of varying concentrations of estradiol. J. Clin. Endocrinol. Metab. 42:432-440.

24. Shaw, R. W., W. R. Butt, and D. R. London. 1975. The effect of oestrogen pretreatment on subsequent response to luteinizing hormone releasing hormone in normal women. Clin. Endocrinol. 4:297-304.

25. Stumpf, P. G., J. Maruca, R. J. Santen, and L. M. Demers. 1982. Development of a vaginal ring for achieving physiologic levels of 17Bestradiol in hypoestrogenic women. J. Clin. Endocrinol. Metab. 54:208210.
26. Samojlik, E., J. D. Veldhuis, S. A. Wells, and R. J. Santen. 1980. Preservation of androgen secretion during estrogen suppression with aminoglutethimide in the treatment of metastatic breast carcinoma. $J$. Clin. Invest. 65:602-612.

27. Winer, B. J. 1971. Statistical Principles in Experimental Design. McGraw-Hill, Inc., New York. 196.

28. Veldhuis, J. D., E. Samojlik, W. S. Evans, A. D. Rogol, C. E. Ridgeway, W. F. Crowley, L. Kolp, E. Checinska, M. A. Kirschner, M. O. Thorner, and P. Stumpf. 1986. Endocrine impact of pure estradiol replacement in postmenopausal women: alterations in anterior pituitary hormone release and circulating sex steroid hormone concentrations. Am. J. Obstet. Gynecol. In press.

29. Kohler, P. O., G. T. Ross, and W. D. Odell. 1968. Metabolic clearance and production rates of human luteinizing hormone in preand post-menopausal women. J. Clin. Invest. 47:38-47.

30. Pepperell, R. J., D. M. de Kretser, and H. G. Burger. 1975. Studies on the metabolic clearance rate and production rate of human luteinizing hormone and on the initial half-time of its subunits in man. J. Clin. Invest. 56:118-126.

31. Veldhuis, J. D., F. Fraioli, A. D. Rogol, and M. L. Dufau. 1986. Metabolic clearance of biologically active luteinizing hormone in man. J. Clin. Invest. 77:1122-1128. 